\title{
Pleiotropic effects of rosuvastatin on microvascular function in type 2 diabetes
}

This article was published in the following Dove Press journal:

Diabetes, Metabolic Syndrome and Obesity:Targets and Therapy

21 January 2010

Number of times this article has been viewed

\author{
Henri K Parson \\ Meredith A Bundy \\ Charlotte B Dublin \\ Amanda L Boyd \\ James F Paulson \\ Aaron IVinik \\ Leonard R. Strelitz Diabetes Center, \\ Department of Internal Medicine \\ Eastern Virginia Medical School, \\ Norfolk, Virginia, USA
}

Correspondence: Henri K Parson EVMS - Strelitz Diabetes Center, 855 West Brambleton Avenue, Norfolk,VA 235I0, USA Email parsonhk@evms.edu

\begin{abstract}
Rosuvastatin is known to reduce low-density lipoprotein (LDL)-cholesterol and improve endothelial function. In addition to lipid-lowering, statins may exert pleiotropic (nonlipid lowering) effects on microvascular function. We compared the neurophysiological and vascular responses of dietary control and treatment with $10 \mathrm{mg}$ of rosuvastatin in 16 subjects with neuropathy and established type 2 diabetes. Skin blood flow (SkBF) measurements were measured at baseline, after 18 weeks of diet, and after 18 weeks of diet and treatment with rosuvastatin in response to local warming and ischemia reperfusion. The study results show that total cholesterol $(196.50 \pm 8.02$ to $134.88 \pm 10.86 \mathrm{mg} / \mathrm{dL})$ and LDL-cholesterol $(114 \pm 10.4$ to $63.4 \pm 8.48 \mathrm{mg} / \mathrm{dL}$ ) decreased significantly after 18 weeks of rosuvastatin, but not after 18 weeks of diet. Neuropathy scores decreased from $8.34 \pm 1.26$ at baseline to $6.00 \pm 0.90$ after rosuvastatin treatment. Basal SkBF was significantly different from baseline, $6.81 \pm 0.42$ to $9.92 \pm 0.78$ after rosuvastatin treatment $(P \leq 0.001)$. These results indicate that rosuvastatin therapy positively changed basal SkBF and measures of neurovascular function. Although there was a profound lipid lowering, it is not clear that this mediated the increases in SkBF and decreases in neuropathy scores.
\end{abstract}

Keywords: neurovascular function, rosuvastatin, diabetes

\section{Introduction}

Metabolic abnormalities in diabetes are associated with microvascular dysfunction. We have documented the existence of defective blood flow in the skin of people with type 2 diabetes that cosegregates with dyslipidemia, hypertension, insulin resistance, and markers of inflammation. ${ }^{1,2}$ Impaired blood flow, which often precedes the development of diabetes, is a major contributor to nerve dysfunction and skin integrity which leads to foot ulcers and amputation. Improving the microvascular perfusion of peripheral nerves is of particular importance since diabetic neuropathy is the main contributor to lower extremity amputations in the US. ${ }^{3}$

Rosuvastatin, which has been widely used to treat hypercholesterolemia, selectively competes to inhibit HMG-CoA reductase. Clinical trial data have reported that patients achieve significant reductions in low-density lipoprotein (LDL)-cholesterol after being treated with $10 \mathrm{mg}$ rosuvastatin for 6 weeks. ${ }^{4}$ Patients treated with rosuvastatin have been shown to not only attain their cholesterol goals compared to patients taking other statins, ${ }^{5}$ but also achieve significant improvement in endothelial function. ${ }^{6}$ This is especially important since elevated plasma lipids and oxidative stress markers are risk factors for neuropathy. ${ }^{7}$ Rosuvastatin has also been shown to significantly reduce the progression of maximum carotid intima-media thickness. ${ }^{8}$ In the ASTEROID trial, 
Nissen and colleagues reported a significant regression of coronary atherosclerosis in patients when placed on highintensity rosuvastatin therapy. ${ }^{9}$

The benefits of statin therapy for lipid control are well known, but there is less known about how this class of drugs affects microvascular function and how this relates to lipid lowering. Statins have been shown to have nonlipid effects on microvascular perfusion. Most recently, a study by Medina et al evaluated the pleiotropic effects of simvastatin on retinal microvascular endothelium and determined that simvastatin offered the beneficial effect of reducing ischemia. ${ }^{10}$ Another study by Fichtlscherer et al showed the positive effects of statins, not ezetimibe, on endothelial function in patients with coronary artery disease. ${ }^{11}$ In addition, there are some reports that show statins actually improve neurovascular function. ${ }^{12}$ This improvement has been described to be independent of the changes in serum cholesterol which involve nonlipid mechanisms that decrease smooth muscle cell migration and proliferation, as well as decrease the in vitro accumulation of macrophages. ${ }^{13}$ Statins have not only been shown to decrease the inflammatory response by decreasing the production of proinflammatory cytokines such as C-reactive protein and interleukin 6 , but also improve vasomotor function. ${ }^{14}$ The addition of mevolonate, the HMG CoA reductase precursor, significantly reduced the improvement in vascular function, implying that the vascular benefits are not related to lipid concentrations. ${ }^{15}$ Using an animal model of diabetes, Cameron and colleagues have demonstrated that rosuvastatin corrects the sciatic motor and saphenous sensory (large fiber) nerve conduction defect and sciatic endoneurial blood flow, thus improving microvascular function. ${ }^{16}$

The objective of this study was to determine the efficacy of 18 weeks of $10 \mathrm{mg} /$ day oral rosuvastatin therapy superimposed on an American Diabetes Association (ADA) diet on endothelial-dependent and heat-induced vasodilation in subjects with type 2 diabetes and neuropathy.

\section{Methods}

\section{Patient population}

This study was a within-subject repeated measures design that compared the neurovascular responses of 16 subjects with type 2 diabetes and neuropathy at baseline, after 18 weeks of an ADA diet and then 18 weeks of diet and rosuvastatin. Initially, 22 subjects were enrolled, but 4 chose to discontinue participation, one whom experienced dizziness and another experienced burning in the upper extremities. Two other subjects were excluded because they exhibited a number of baseline clinical measures outside the range defined for inclusion. Inclusion criteria included LDL-cholesterol levels above $100 \mathrm{mg} / \mathrm{dL}$ and a minimum of 3 years after diagnosis of type 2 diabetes.

Subjects with microalbuminuria, recent myocardial infarction or cerebrovascular incident, such as stroke within the previous 6 months were excluded from the study because macrovascular disease could affect the microcirculatory responsiveness of the neurovascular measurements and such subjects were likely to be taking statins. Subjects using statins as well as bile acid sequestrants, fibric acid derivatives, and antacids were also excluded. Subjects were allowed the stable use (3 months or more) of angiotensinconverting enzyme (ACE) inhibitors, angiotensin-receptor blockers (ARBs), and other hypertensive agents, and dosage schedule was not changed during the course of the study. Subjects' were maintained on their diabetes-treatment regimen which consisted of a combination of oral agents (metformin, thiazolidinediones, and sulfonylureas), insulin, and diet. The study protocol was reviewed and approved by the Institutional Review Board of Eastern Virginia Medical School and all subjects gave voluntary informed written consent before participation.

\section{Assessment of neurovascular function}

Neurophysiological responses were measured at baseline, after 18 weeks of dietary control, and after 18 weeks of treatment with $10 \mathrm{mg}$ of rosuvastatin. This time course was chosen because previously, we have demonstrated that it is feasible to pharmacologically alter subjective and objective measures of neurovascular function in 18 weeks. ${ }^{1,17,18}$ The primary efficacy measures were skin perfusion. Vascular responses were measured non-invasively using laser Doppler techniques. ${ }^{19}$ Laser Doppler flow (LDF) measurements are a reliable index of SkBF and are uninfluenced by blood flow in the underlying muscle. ${ }^{20}$ The Periflux Master Unit PF4001-2 and the Peritemp heating module with sensor PF4005-3 (Perimed, Inc., Smithtown, NY, USA) were used. Skin blood flow (SkBF) was measured at the brachial artery, medial to the bicipital tendon and over the fingertip in response to five minutes of upper arm occlusion. SkBF was measured on the dorsum of the foot and the plantar surface of the great toe in response to heat. Heat was applied for 10 minutes at $32{ }^{\circ} \mathrm{C}, 10$ minutes at $40{ }^{\circ} \mathrm{C}$, and 20 minutes at $44{ }^{\circ} \mathrm{C}$ to give a total testing time of 40 minutes. Secondary measures also included nerve conduction testing, complete physical, and neurologic examinations. 
Nerve conduction testing was used to measure the nerve conduction velocity (NCV) and amplitudes of specific nerves using the NeuroMax (Xltek Inc., Ontario, Canada). The left peroneal, sural nerves, and left ulnar sensory responses were evaluated for each subject. This battery of electrophysiological tests was used to determine differences in neural activity as well as eliminate other causes of neuropathy. All subjects received a complete pre and post treatment neurological examination. This exam is comprised of six components including the neurological symptom score, cranial nerve function, and an evaluation of muscle weakness, muscle wasting, reflexes and sensory function of upper and lower limbs bilaterally. The six components of the neurological exam were added to generate a total neuropathy score, which was analyzed for changes before and after rosuvastatin therapy. A subanalysis was also performed on the motor and sensory components of the exam. The neurological exam contains all components of the nerve impairment score - lower limb (NIS-LL), originally developed by Dyck and colleagues. ${ }^{21}$ Therefore, we were also able to do an analysis of the total NIS-LL and each of its elements. Secondary measures included fasting blood tests for metabolic parameters (insulin, C-peptide, glucose, hemoglobin $\mathrm{A}_{1 \mathrm{c}}$ $\left.\left[\mathrm{HbA}_{1 \mathrm{c}}\right]\right)$ as well as safety measures to monitor liver enzymes (within three times the upper limit of normal) and kidney function (creatinine within normal limits). Quantitative sensory tests (QST) were used to evaluate peripheral sensory perception. These tests measure vibratory, proprioceptive, tactile, pain, and thermal nerve function. Autonomic function tests were used to evaluate autonomic neuropathy and are based on detection of heart rate and blood pressure response to a series of breathing maneuvers.

\section{ADA diet}

All subjects were instructed to follow a specified nutritional diet established by the ADA.22 The nutritional guidelines recommended by the ADA include eating carbohydrates from fruits, vegetables, whole grains, legumes and low-fat milk. They also include eating fiber-rich foods and nonfried fish, as well as limiting saturated fats ( $<7 \%$ total caloric intake), trans fats, and cholesterol $(<200 \mathrm{mg} /$ day $)$. A certified dietitian provided dietary support approximately every 6 weeks. All subjects continued to follow dietary guidelines during rosuvastatin therapy.

\section{Statistical analysis}

To analyze the results, paired t-tests were used to assess within-subjects change between the three study phases across all study variables. Matched pairs with missing data points were discarded therefore some variables have an $\mathrm{N}<16$. Associations between clinical values and various measures of neuropathy and associated variables were examined with Pearson correlations. $P$ values less than or equal to 0.05 were regarded as significant. All data analyses were conducted using SPSS version 15 software.

\section{Results}

Sixteen subjects were included in this study (10 females and 6 males): 11 Caucasian, 4 African American, and 1 Hispanic. Average age of the subjects was $56.08 \pm 2.15$ years, with $8.42 \pm 0.89$ years average length of diabetes. Laboratory parameters are listed in Table 1.

There were no significant differences in the lipid profile after ADA diet alone. After the addition of rosuvas-

Table I Summary of demographic and laboratory results

\begin{tabular}{|c|c|c|c|c|}
\hline $\begin{array}{l}\text { Demographic and Lab } \\
\text { characteristics }\end{array}$ & Normal values & Pre-treatment & ADA diet & $\begin{array}{l}\text { ADA diet and } \\
\text { rosuvastatin }\end{array}$ \\
\hline Body mass index & $19-25 \mathrm{~kg} / \mathrm{m}^{2}$ & $36.61 \pm 2.37$ & $36.88 \pm 2.2$ & $36.25 \pm 2.12$ \\
\hline Systolic blood pressure & $<120 \mathrm{mmHg}$ & $|42.44 \pm 5.0|$ & $132.94 \pm 5.07$ & $130.0 \pm 4.84$ \\
\hline Diastolic blood pressure & $<80 \mathrm{mmHg}$ & $79.94 \pm 2.36$ & $74.5 \pm 2.53$ & $74.75 \pm 2.66$ \\
\hline $\begin{array}{l}\text { Fasting plasma glucose } \\
(\mathrm{mg} / \mathrm{dL})\end{array}$ & $70-110 \mathrm{mg} / \mathrm{dL}$ & $157.94 \pm 16.22$ & $153.67 \pm 21.62$ & $176.19 \pm 19.48$ \\
\hline C Peptide $(\mathrm{ng} / \mathrm{mL})$ & $0.9-4 \mathrm{ng} / \mathrm{mL}$ & $3.02 \pm 0.56$ & $3.48 \pm 0.48$ & $3.8 \mathrm{I} \pm 0.6 \mathrm{I}^{*}$ \\
\hline $\mathrm{HbA}_{\mathrm{lc}}(\%)$ & $4.3 \%-6.1 \%$ & $8.09 \pm 0.47$ & $7.84 \pm 0.56^{\#}$ & $8.96 \pm 0.62 *$ \\
\hline Insulin (ulU/mL) & $5-15 \mathrm{ulU} / \mathrm{mL}$ & $13.40 \pm 2.84$ & $12.62 \pm 3.09$ & $10.48 \pm 3.21$ \\
\hline Triglycerides (mg/dL) & $10-150 \mathrm{mg} / \mathrm{dL}$ & $|28.8| \pm \mid 4.58$ & $128.58 \pm 19.76$ & $127.25 \pm 20.74$ \\
\hline Total cholesterol (mg/dL) & $0-200 \mathrm{mg} / \mathrm{dL}$ & $196.50 \pm 8.02$ & $193.42 \pm 11.40^{\#}$ & $134.88 \pm 10.86^{*}$ \\
\hline HDL-C (mg/dL) & $35-95 \mathrm{mg} / \mathrm{dL}$ & $49.41 \pm 5.40$ & $51.0 \pm 4.94$ & $49.25 \pm 4.47$ \\
\hline LDL-C (mg/dL) & $50-160 \mathrm{mg} / \mathrm{dL}$ & $113.7 \pm 13.1$ & $113.63 \pm 9.77^{\#}$ & $60.19 \pm 8.56^{*}$ \\
\hline
\end{tabular}

Values are mean $\pm \mathrm{SE}, \mathrm{P} \leq 0.05$. "Results are significant from ADA diet combined with rosuvastatin. *Results are significant from pre-treatment to ADA diet combined with rosuvastatin.

Abbreviations: $\mathrm{HbA}_{\mathrm{Ic}}$, hemoglobin $\mathrm{A}_{\mathrm{Ic}}$; $\mathrm{HDL}-\mathrm{C}$, high density lipoprotein; LDL-C, low density lipoprotein. 
tatin, however, significant differences in lipid levels were shown with LDL cholesterol improving by $47 \%$ and total cholesterol improving by $31 \%$. Other significant values included an increase in $\mathrm{C}$-peptide and $\mathrm{HbA}_{1 \mathrm{c}}$. The ADA diet for 18 weeks produced no significant differences in any laboratory parameter from pretreatment (baseline) to ADA diet (Table 1).

Mean baseline median skin blood flow of the foot dorsum $(\mathrm{n}=16)$, a primary endpoint, increased significantly from study start to the end of rosuvastatin therapy phase (delta $=2.76 \pm 0.68, P=0.001)$ (Figure 1). Similar trends were observed on the foot dorsum at $40^{\circ} \mathrm{C}$ median (delta $3.4 \pm 1.52$,
$P=0.04)$ and $44{ }^{\circ} \mathrm{C}$ peak $($ delta $=36.2 \pm 13.1, P=0.015)$. No significant differences in skin blood flow measured over the toe after occlusion were observed.

Treatment with rosuvastatin improved the total neuropathy score (Table 2 ). Bilateral reductions in total neuropathy scores were observed from study start to the end of rosuvastatin treatment phase (delta $=-2.33 \pm 1.1$, $P=0.05)$. The NIS-LL was initially analyzed for all 16 patients. Another analysis was performed after the removal of one outlier (defined as three standard deviations from the mean). This patient had a significant change in health status that resulted in a large change in her physical

A

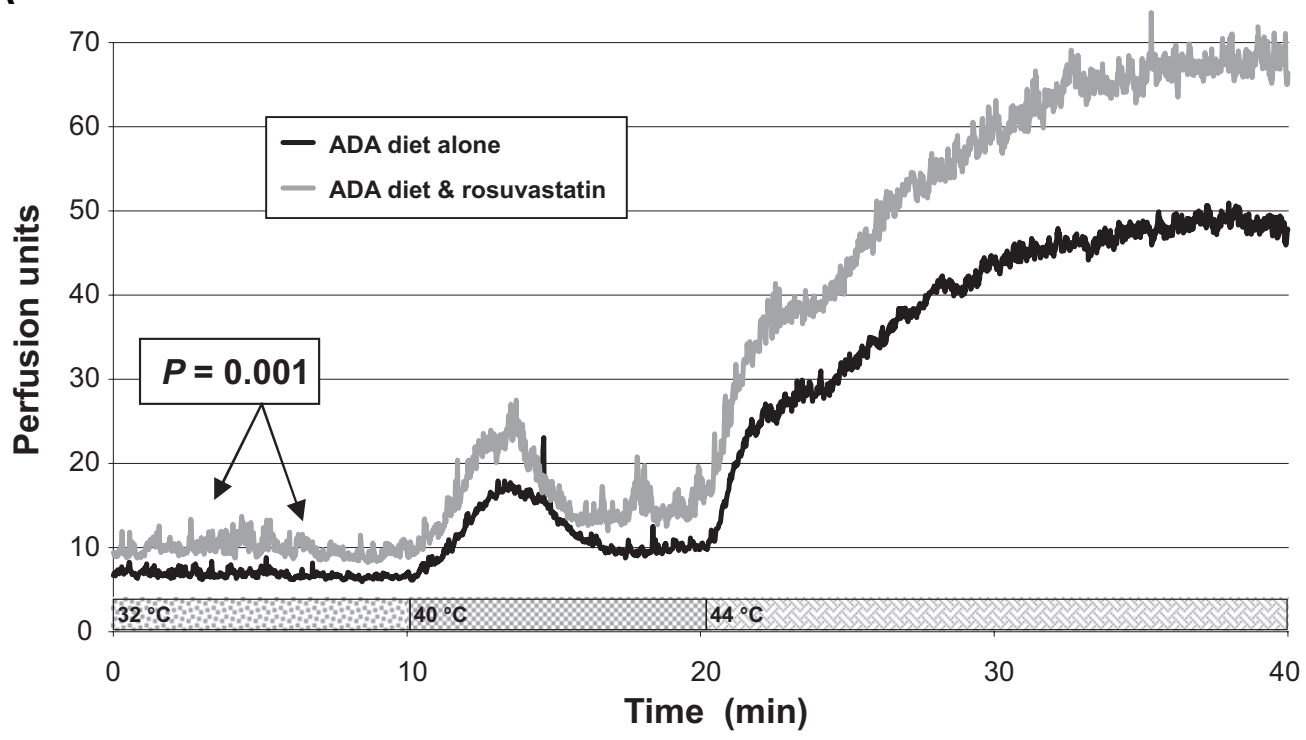

B

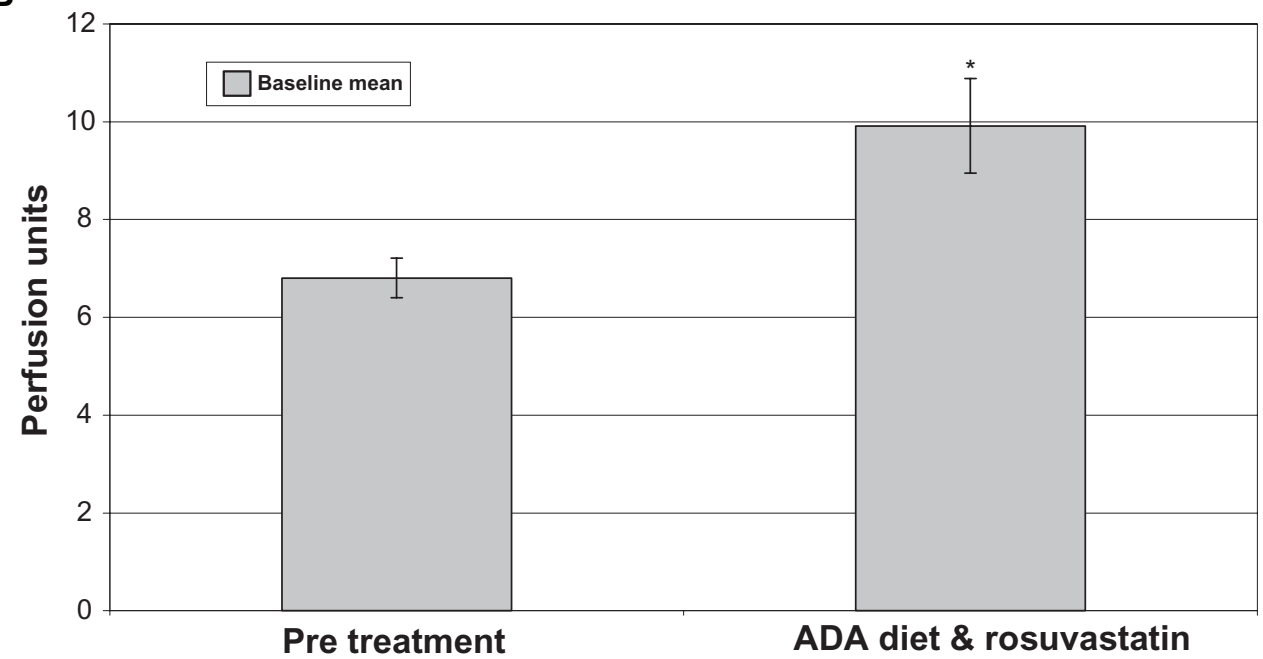

Figure I Skin blood flow graphs. A) Skin perfusion of the foot dorsum (during heating) at baseline (American Diabetes Diet [ADA] diet alone) and after I8 weeks of ADA diet and rosuvastatin $(\mathrm{N}=16)$. B) A bar graph representation of the significant differences in baseline blood flow.

*Results are significant from pre-treatment to ADA diet combined with rosuvastatin, $P=0.00 \mathrm{I}$. 
Table 2 Neurological symptom and impairment scores

\begin{tabular}{llll}
\hline $\begin{array}{l}\text { Neurologic Impairment } \\
\text { measures }\end{array}$ & Pre-treatment & $\begin{array}{l}\text { ADA diet and } \\
\text { rosuvastatin }\end{array}$ & P value \\
\hline Neurologic symptom score & $3.09 \pm 0.72$ & $2.03 \pm 0.42$ & 0.09 \\
Sensory score & $3.56 \pm 0.60$ & $2.56 \pm 0.49$ & 0.13 \\
Motor score & $1.69 \pm 0.30$ & $1.41 \pm 0.25$ & 0.31 \\
Total neuropathy score & $8.34 \pm 1.26$ & $6.00 \pm 0.90$ & $0.05^{*}$ \\
NIS-LL $(\mathbf{N}=15)$ & & & 0.022 \\
NIS-LL Reflexes $(n=15)$ & $1.87 \pm 0.14$ & $1.37 \pm 0.23$ & 0.20 \\
NIS-LL Muscle weakness $(n=15)$ & $0.73 \pm 0.37$ & $1.27 \pm 0.40$ & 0.004 \\
NIS-LL Sensation $(n=15)$ & $6.40 \pm 0.76$ & $3.27 \pm 0.86$ & 0.007 \\
NIS-LL Total score $(n=15)$ & $9.00 \pm 1.00$ & $5.9 \pm 0.94$ & \\
\hline
\end{tabular}

Values are mean $\pm \mathrm{SE}, \mathrm{p} \leq 0.05$. *Results are significant from pre-treatment to ADA diet combined with rosuvastatin. *During the analysis of the NIS-LL and its components, one person was a clear outlier and was excluded from the analysis.

Abbreviation: NIS-LL, nerve impairment score-lower limb.

condition unrelated to rosuvastatin therapy. This change was not reflected in other neurovascular measures. There was a significant improvement in the reflex component of the NIS-LL $(P=0.02)$, sensation component of the NISLL (0.004), and the NIS-LL total $(P=0.007)$. QST and autonomic function tests did not significantly improve after ADA diet or treatment with rosuvastatin (Table 3). There were also no significant differences in nerve conduction measurements (Table 3). These results indicate that 18 weeks of rosuvastatin therapy improves certain aspects of neurovascular function and did not cause adverse changes in quantitative electrophysiological measurements of nerve function. Correlations were sought between the effects of rosuvastatin on LDL-cholesterol and measures of neurovascular function, but none were found.

\section{Discussion}

The cardinal findings in this study were that 18 weeks of rosuvastatin significantly improved the lipid profile of all subjects, while improving basal skin blood flow and the total neuropathy score assessed during clinical neurological examination. In our study 18 weeks of rosuvastatin therapy lowered LDL-cholesterol and total cholesterol by $47 \%$ and $31 \%$, respectively. Regression analysis of the improvements in total and LDL-cholesterol did not, however, support a direct correlation with the improvement in neurovascular function

Table 3 Effects of American Diabetes Association (ADA) diet and ADA diet + rosuvastatin on somatic and autonomic nerve function

\begin{tabular}{llll}
\hline Nerve function measures & Pre-treatment $(\mathbf{n}=\mathbf{1 6})$ & ADA diet $(\mathbf{n}=\mathbf{1 6})$ & ADA diet + rosuvastatin $(\mathbf{n}=\mathbf{1 6})$ \\
\hline Sural amplitude & $8.43 \pm 1.60^{*}$ & $7.33 \pm 1.25$ & $8.68 \pm 1.48$ \\
Sural CV & $39.12 \pm 2.75$ & $36.90 \pm 3.78$ & $36.06 \pm 3.59$ \\
Peroneal amplitude & $4.06 \pm 0.68$ & $4.08 \pm 0.68$ & $3.97 \pm 0.68$ \\
Peroneal CV & $41.69 \pm 1.20$ & $42.35 \pm 1.21$ & $41.96 \pm 1.58$ \\
Vibration & $16.59 \pm 2.77$ & $18.81 \pm 4.37$ & $19.93 \pm 4.10$ \\
Pressure & $3.53 \pm 0.22$ & $3.47 \pm 0.18$ & $3.64 \pm 0.22$ \\
Cold sensation & $6.41 \pm 0.91$ & $6.16 \pm 0.95$ & $6.16 \pm 0.93$ \\
Warm sensation & $7.96 \pm 1.07$ & $6.96 \pm 1.03$ & $7.61 \pm 1.04$ \\
Cold pain & $17.56 \pm 3.86$ & $18.78 \pm 3.61$ & $19.68 \pm 3.11$ \\
Heat pain & $15.17 \pm 0.95$ & $14.67 \pm 1.15$ & $13.15 \pm 0.93$ \\
E/I ratio & $1.26 \pm 0.14$ & $1.14 \pm 0.03$ & $1.20 \pm 0.08$ \\
Valsalva ratio & $1.25 \pm 0.05$ & $1.23 \pm 0.06$ & $1.57 \pm 0.31$ \\
30/I5 ratio & $3.81 \pm 1.29$ & $3.97 \pm 0.93$ & $2.86 \pm 0.57$ \\
\hline
\end{tabular}

Abbreviations: CV, conduction velocity; autonomic function measures of heart rate variability during: E/I ratio, expiration/inspiration ratio; Valsalva ratio, Valsalva maneuver (forcible exhalation against a closed airway); 30/15 ratio, electrocardiogram R-R interval to upright posture. 
and neuropathy symptoms. Our results indicate significant improvements in microvascular perfusion despite actual deterioration in glucose or $\mathrm{HbA}_{1 \mathrm{c}}$ levels and an increase in $\mathrm{C}$-peptide. This finding has been previously reported ${ }^{23,24}$ and was clinically insignificant in this study. Diabetes control should be carefully monitored when patients receive rosuvastatin therapy. Rosuvastatin did improve neuropathy scores $(P=0.007)$, but we found no significant changes in objective measures, which include nerve conduction, autonomic neuropathy testing, or QST results. It is also important to mention that several studies have reported an improvement in nerve function with stringent diet control alone..$^{25,26}$ In the study reported here, there was a trend towards improved microvascular function in many parameters on diet alone; however, none of these were significant without the addition of rosuvastatin therapy.

In previous studies, we have shown that there is a profound defect in SkBF in individuals with type 2 diabetes that directly correlates with nerve dysfunction, indices of insulin resistance, triglyceride levels and markers of inflammation. ${ }^{1,2,27}$ The significant improvement in skin perfusion observed with rosuvastatin therapy may be linked to the balance between nitric oxide synthesis and endothelin regulation. ${ }^{28}$ Rosuvastatin may alter the balance in favor of vasodilation by increasing endothelial-derived nitric oxide (NO) and downregulating endothelin 1, a vasoconstrictor. A short-term study on lipid-lowering therapy with statins in humans showed improvements in endothelial function and nitric oxide availability. In 41 hypercholesterolemic subjects, a significant decrease in LDL-cholesterol improved endothelium-dependent vasodilation and decreased oxidative stress. ${ }^{15}$ The decrease in lipid levels during rosuvastatin therapy with the subsequent improvement in vascular function might imply that lipotoxicity and increases in oxidative stress cause microvascular dysfunction, although this theory remains controversial. In our study, however, there was no direct correlation between the indices of improved neurovascular function and the changes in lipoprotein metabolism.

In previous studies, we have shown that the insulin sensitizers, rosiglitazone ${ }^{27}$ and pioglitazone ${ }^{29}$ improve blood flow marginally, but have diametrically opposite effects on nitrosative stress. Rosiglitazone increases NO while improving blood flow, ${ }^{27}$ whereas pioglitazone reduced nitrosative stress $^{29}$ while increasing blood flow and had profound effects on lipids. ${ }^{30,31}$ Similarly, in this study, we show improvement in nerve function and blood flow which were independent of the changes in total and LDL-cholesterol. It is quite plausible that there may be effects of statins on microvascular function outside of their lipid-lowering properties.

In a recent report from Freemantle, Australia, Davis and colleagues conducted a biphasic study, which concluded that statin and fibric acid derivatives reduced the overall risk for developing neuropathy. The cross-sectional phase of the study evaluated 1294 patients with type 2 diabetes (average age of 63.8 and 4 years of diabetes duration) of which $31 \%$ of patients had peripheral neuropathy at baseline. Approximately $7 \%$ of these patients were on statin therapy and $4 \%$ were on fibrate therapy. After the independent predictors of age, height, duration of diabetes, systolic blood pressure, abdominal girth, and obesity were considered, the study concluded that fibric acid therapy reduced the likelihood of neuropathy $(P<0.001)$. In the longitudinal phase with a 5 -year follow up, 531 patients with type 2 diabetes ( $26 \%$ had peripheral sensory neuropathy at baseline and $74 \%$ were free of neuropathy) were examined. The best predictors of freedom from development of neuropathy were time dependent statin $(P=0.019)$ and fibrate use $(P=0.042){ }^{32}$

Similar findings were reported in the Steno Memorial study by Gaede and colleagues in which multifactorial therapy controlling blood pressure, $\mathrm{HbA}_{1 \mathrm{c}}$, and lipids using statins reduced the likelihood of development of autonomic neuropathy by $66 \% .{ }^{33}$ While the Field study failed to demonstrate a reduction in macrovascualr disease using fibrates, it did show a reduction of microvascular disease even when controlling for statin use. ${ }^{34}$

There are numerous animal studies that further support the beneficial effects of rosuvastatin on microvascular function. Nangle et al examined the effects of rosuvastatin on corpus cavernosum and aorta from streptozotocin-induced diabetic mice. These animals were treated with mevalonate to assess the dependence of rosuvastatin's effects on HMG-CoA reductase blockade. The diabetes induced reduction in NO mediated endothelium-dependent relaxation of the cavernosum and aorta were completely reversed by rosuvastatin. Co-treatment with mevalonate inhibited this beneficial action and total plasma cholesterol was unaltered by diabetes or treatment, supporting the theory of improved vascular function with statins through non-lipid related mechanisms. ${ }^{35}$ A second study, reported that rosuvastatin corrected the sciatic motor and saphenous sensory (large fiber) nerve conduction defect, sciatic endoneurial blood flow, thermal hyperalgesia (small fiber) and deficits in superior cervical ganglion. It also improved nitrergic and endothelium-derived hyperpolarizing factor-mediated blood flow in corpora cavernosa in diabetic mice. ${ }^{16}$ Yet another 
animal study reported that rosuvastatin exerts important anti-inflammatory effects in rats via inhibition of endothelial cell adhesion molecule expression and that this protective action is facilitated through the release of NO by the vascular endothelium. ${ }^{36}$

There have been several recent studies which described the pleiotropic (nonlipid lowering) effects of statins on microvascular function. In particular, a study conducted by Fichtlscherer et al compared venous plethysmography forearm blood flow responses to acetylcholine and sodium nitroprusside in four groups, de novo ezetimibe monotherapy, ezetimibe as an add on to chronic simvastatin therapy, dose escalation of simvastatin therapy, and de novo simvastatin therapy. ${ }^{11}$ After 4 weeks of lipid-lowering therapy, groups who received ezetimibe monotherapy and ezetimibe as an add-on therapy to simvastatin showed no increase in blood flow responses although LDL-cholesterol levels were significantly reduced. In contrast, 4 weeks of monotherapy with atorvastatin showed lipid changes and significant increases in acetylcholine mediated blood flow. This study illustrated that despite the lipid lowering effects of both agents, only statin therapy displayed a pleiotropic effect of improved vascular function. In addition, Medina et al reports that a low dose simvastatin therapy has a beneficial affect on ischemic retinopathy..$^{10}$ Low concentrations of simvastatin $(0.1 \mu \mathrm{M})$ enhanced microvascular repair, significantly increased proliferation, and promoted migration, sprouting, and tubulogenesis in retinal microvascular endothelial cells. These results show that statins may reduce ischemia and promote angiogenic repair, thus preventing neovascularization. High-dose simvastatin therapy appeared to hinder this reparative process.

Our study shows that rosuvastatin therapy appears to play a role in the microvascular defect in the skin and also improves other measures of neurovascular function, which appears to be irrespective of the changes in LDLcholesterol. Since our study investigated only rosuvastatin, we cannot conclude that this is a class effect for all statins. In addition, there may be additional beneficial results of rosuvastatin on vascular function that were not seen due to sample size. Further investigation is needed to evaluate the mechanistic aspects of rosuvastatin and to document whether the effects on nerve function hold true in long term statin therapy. Studies are needed using agents that affect the individual components of disturbed lipoprotein metabolism as well as other components of the metabolic syndrome that are conducive to the development of microvascular dysfunction. ${ }^{37}$

\section{Acknowledgments}

This research was an investigator initiated study supported by a grant from the Investigator-Sponsored Study Program of AstraZeneca.

\section{Disclosures}

The authors disclose no conflicts of interest.

\section{References}

1. Vinik AI, Erbas T, Park TS. Methods for evaluation of peripheral neurovascular dysfunction. Diabetes Technol Ther. 2001;3:29-50.

2. Vinik A, Erbas T, Park T, Stansberry K, Scanelli J, Pittenger G. Dermal neurovascular dysfunction in type 2 diabetes. Diabetes Care. 2001;24:1468-1475.

3. Holzer SE, Camerota A, Martens L, Cuerdon T, Crystal-Peters J, Zagari M. Costs and duration of care for lower extremity ulcers in patients with diabetes. Clin Ther. 1998;20:169-181.

4. Lloret R, Ycas J, Stein M, Haffner S. Comparison of rosuvastatin versus atorvastatin in Hispanic-Americans with hypercholesterolemia (from the STARSHIP trial). Am J Cardiol. 2006;98:768-773.

5. Bullano MF, Kamat S, Wertz DA, et al. Effectiveness of rosuvastatin versus atorvastatin in reducing lipid levels and achieving lowdensity-lipoprotein cholesterol goals in a usual care setting. Am J Health Syst Pharm. 2007;64:276-284.

6. Sergienko IV, Samoilenko EI, Masenko VP, et al. Effect of therapy with rosuvastatin on lipid spectrum, factors of inflammation and endothelial function in patients with ischemic heart disease. Kardiologiia. 2006;46:4-8.

7. Cameron NE, Eaton SEM, Cotter MA, Tesfaye S. Vascular factors and metabolic interactions in the pathogenesis of diabetic neuropathy. Diabetologia. 2001;44:1973-1988.

8. Crouse JR III, Raichlen JS, Riley WA, et al. Effect of rosuvastatin on progression of carotid intima-media thickness in low-risk individuals with subclinical atherosclerosis: the METEOR Trial. JAMA. 2007;297:1344-1353.

9. Nissen SE, Nicholls SJ, Sipahi I, et al. Effect of very high-intensity statin therapy on regression of coronary atherosclerosis: The ASTEROID Trial. JAMA. 2006;295:1556-1565.

10. Medina RJ, O'Neill CL, Devine AB, Gardiner TA, Stitt AW. The pleiotropic effects of simvastatin on retinal microvascular endothelium has important implications for ischaemic retinopathies. PLoS One. 2008;3:e2584

11. Fichtlscherer S, Schmidt-Lucke C, Bojunga S, et al. Differential effects of short-term lipid lowering with ezetimibe and statins on endothelial function in patients with CAD: clinical evidence for ,pleiotropic' functions of statin therapy. Eur Heart J. 2006;27:1182-1190.

12. Mason JC. Statins and their role in vascular protection. Clin Sci (Lond). 2003;105:251-266.

13. Bellosta S, Via D, Canavesi M, et al. HMG-CoA reductase inhibitors reduce MMP-9 secretion by macrophages. Arterioscler Thromb Vasc Biol. 1998;18:1671-1678.

14. Koh KK. Effects of statins on vascular wall: vasomotor function, inflammation, and plaque stability. Cardiovasc Res. 2000;47:648-657.

15. John S, Schneider MP, Delles C, Jacobi J, Schmieder RE. Lipid-independent effects of statins on endothelial function and bioavailability of nitric oxide in hypercholesterolemic patients. Am Heart J. 2005;149:473.

16. Cameron N, Cotter M, Inkster M, and Nangle M. Looking to the future: diabetic neuropathy and effects of rosuvastatin on neurovascular function in diabetes models. Diabetes Res Clin Pract. 2003;61:S35-S39.

17. Pittenger G, Simmons K, Anandacoomaraswamy D, Rice A, Barlow P, Vinik A. Topiramate improves intraepidermal nerve fiber morphology and quantitative neuropathy measures in diabetic neuropathy patients. [abstract] J Peripher Nerve System. 2005;10 Suppl 1. 
18. Vinik A, Erbas T, Stansberry KB, Pittenger G. Small fiber neuropathy and neurovascular disturbances in diabetes mellitus. Exp Clin Endocrinol Diabetes. 2001;109:S451-S473.

19. Stansberry KB, Shapiro SA, Hill MA, McNitt PM, Meyer MD, Vinik AI. Impaired peripheral vasomotion in diabetes. Diabetes Care. 1996;19: $715-721$.

20. Saumet JL, Kellogg DL, Taylor WF, Johnson JM. Cutaneous laserDoppler flowmetry: influence of underlying muscle blood flow. J Appl Physiol. 1998;65:478-481.

21. Dyck PJ. Detection, characterization and staging of polyneuropathy: assessed in diabetes. Muscle Nerve. 1988;11:21-32.

22. Schafer RG, Bohannon B, Franz MJ, et al. Diabetes nutrition recommendations for health care institutions. Diabetes Care. 2004;27 Suppl 1: S55-S57.

23. Betteridge DJ, Gibson JM. Effects of rosuvastatin on lipids, lipoproteins and apolipoproteins in the dyslipidaemia of diabetes. Diabet Med. 2007;24:541-549.

24. Rajpathak SN, Kumbhani DJ, Crandall J, Barzilai N, Alderman M, Ridker PM. Statin therapy and risk of developing type 2 diabetes: a meta-analysis. Diabetes Care. 2009;32:1924-1929.

25. Smith AG, Russell J, Feldman EL, et al. Lifestyle intervention for prediabetic neuropathy. Diabetes Care. 2006;29:1294-1299.

26. McCarty MF. Favorable impact of a vegan diet with exercise on hemorheology: implications for control of diabetic neuropathy. Med Hypotheses. 2002;58:476-486.

27. Vinik AI, Stansberry KB, Barlow PM. Rosiglitazone treatment increases nitric oxide production in human peripheral skin: a controlled clinical trial in patients with type 2 diabetes mellitus. J Diabetes Complications. 2003; 17:279-285.

28. Gulcan E, Gulcan A, Erbilen E, Toker S. Statins may be useful in diabetic foot ulceration treatment and prevention. Med Hypotheses. 2007;69:1313-1315.
29. Vinik A, Stansberry K. Pioglitazone treatment improves nitrosative stress and microvascular function. Diabetes. 2003;52 Suppl 1:A478.

30. Chiquette E, Ramirez G, DeFronzo R. A meta-analysis comparing the effect of thiazolidinediones on cardiovascular risk factors. Arch Intern Med. 2004;164:2097-2104.

31. Goldberg RB, Kendall DM, Deeg MA, et al. A comparison of lipid and glycemic effects of pioglitazone and rosiglitazone in patients with type 2 diabetes and dyslipidemia. Diabetes Care. 2005;28:1547-1554.

32. Davis TM, Bruce DG, Davis WA. Prevalence and prognostic implications of the metabolic syndrome in community-based patients with type 1 diabetes: The Fremantle Diabetes Study. Diabetes Res Clin Pract. 2007;78:412-417.

33. Gaede P, Vedel P, Larsen N, Jensen G, Parving H, Pedersen O. Multifactorial intervention and cardiovascular disease in patients with type 2 diabetes. N Engl J Med. 2003;348:383-393.

34. Keech AC, Mitchell P, Summanen PA, et al. Effect of fenofibrate on the need for laser treatment for diabetic retinopathy (FIELD study): a randomised controlled trial. Lancet. 2007;370:1687-1697.

35. Nangle MR, Cotter MA, Cameron NE. Effects of rosuvastatin on nitric oxide-dependent function in aorta and corpus cavernosum of diabetic mice: relationship to cholesterol biosynthesis pathway inhibition and lipid lowering. Diabetes. 2003;52:2396-2402.

36. Stalker TJ, Lefer AM, Scalia R. A new HMG-CoA reductase inhibitor, rosuvastatin, exerts anti-inflammatory effects on the microvascular endothelium: the role of mevalonic acid. Br J Pharmacol. 2001;133:406-412.

37. Pittenger G, Mehrabyan A, Simmons K, Rice A, Barlow P, Vinik A. Small fiber neuropathy is associated with the metabolic syndrome. Metab Syndr Relat Disord. 2005;3:113-121.

\section{Publish your work in this journal}

Diabetes, Metabolic Syndrome and Obesity: Targets and Therapy is an international, peer-reviewed open-access journal committed to the rapid publication of the latest laboratory and clinical findings in the fields of diabetes, metabolic syndrome and obesity research. Original research, review, case reports, hypothesis formation, expert opinion and commentaries are all considered for publication. The manuscript management system is completely online and includes a very quick and fair peer-review system, which is all easy to use. Visit http://www.dovepress.com/testimonials.php to read real quotes from published authors. 